Published in 2014 by Geographical Research 52(2):146-156.

\title{
Politically engaged geographical research with the community sector: is it encouraged by Australia's higher education and research institutions?
}

Sue Jackson and Louise Crabtree

Key words: policy, research impact, higher education, community sector.

\section{Abstract}

With the application of neoliberal thinking to the higher education sector, measures of research quality and utility have proliferated in efforts to increase academic accountability, innovation and contributions to public policy. We intend to re-ignite discussion about community activism and the role of the academic in response to trends in higher education policy and recent debate in Australia about research quality assessment and policy relevance. We challenge the common portrayal of the public sector as the sole locus of policy-making and argue the case for greater recognition of the role of the community sector and its research partners in policy development and implementation; one that is not given due attention in the discourse on, or measures of, research value and impact. Informed by recent literature on governance and interpretative approaches to policy analysis, we draw on our combined experience conducting research with two Australian movements at the forefront of reforms to property rights institutions, legal standards, and norms relating to social and economic equity, to outline the institutional tensions and structural impediments facing researchers working with the non-government sector. The paper documents the progressive roles the academic can play in such work, arguing that institutional change is required within the tertiary sector to support researchers to build 
Published in 2014 by Geographical Research 52(2):146-156.

closer, more trusting research partnerships in which due attention is given to social impact and relevance.

\subsection{Introduction}

With the emergence of neoliberal management within the global higher education sector, measures of research quality and utility have proliferated in widespread efforts to increase academic accountability, innovation and contributions to public policy. Under increasingly managerialist models of governance, in which universities are required to 'market' their worth to the knowledge economy and 'in effect continuously' negotiate with central government over funding, there is now a strong focus on 'performance' as measured by quantitative targets (Castree, 2010; Radice, 2013). In the UK, for example, the new Research Excellence Framework will include a ' $20 \%$ impact component' in funding decisions from 2014 (Norrie, 2012). Notwithstanding greater emphasis on policy impact in research performance measures, criticism of the extent to which research benefits society continues to be leveled at the research community with some Australian commentators lamenting the failure of academics to contribute to public policy debate, innovation and advancement (Norrie, 2012; Shergold, 2011).

Pannell and Roberts (2009) argue that many researchers in their field of natural resource management aspire to influence policy design and implementation. In response to this aspiration, analyses of effective strategies and approaches to foster productive links between researchers and policy-makers are readily available (e.g Roux et al., 2010; Jacobs, 2002; Beyer, 1997; Jones and Seelig, 2004) and a broad range of reasons for poor uptake of research by policy-makers has been identified (see Briggs, 2006, van Vliet, 2003). Part of 
Published in 2014 by Geographical Research 52(2):146-156.

that literature has more thoroughly investigated conceptions of 'use' and the factors influencing adoption (Gill, 2006; Amara et al., 2004).

Periodically geographers concerned about the discipline's influence have discussed the 'fraught' relationship between research and the policy process (Peck, 1999; Pollard et al., 2000; Gill, 2006; Tickell, 1995). Geographers have encouraged more debate about activism and the academy (Pain, 2014; Batterbury, 2013; Mitchell, 2008; Ward, 2006; Blomley, 1994, 1995; Castree, 1999), describing struggles to find new ways of making academic knowledge accessible and remain committed to community activism in the face of an advancing 'instrumentalisation of academic knowledge' (Castree, 2010, 6).

The debates in geography traverse many facets of the policy-impact issue and, when read collectively, question the 'recurring, sometimes short-sighted perspectives on policy research' (Pain, 2006, 256) that has (re)surfaced in Australia. Geographers, including Pain (2006), argue that policy research 'is not just about working with policy-makers' (p. 250) and encourage scholars to question the value of the subjective term 'policy-relevance', to give proper consideration to what is meant by the 'publics' in public policy (Ward, 2006) and focus on engagement and action-oriented research with a diversity of interest groups.

The recent Australian media debate on research relevance (see Norrie, 2012; Shergold, 2011) could be seen as a welcome way of breathing life into this long-standing argument. However, our intention is to re-ignite discussion about community activism and the role of the academic, especially with regard to policy relevance and research quality assessment. 
Published in 2014 by Geographical Research 52(2):146-156.

We are interested in the effect of institutional expectations and structures on levels of political engagement, on policy development processes and the production of geographical knowledge. This includes the usual suspects of institutional recognition and reward systems, but also institutional systems that affect research praxis, such as funding mechanisms and obligations, training and, importantly, formal ethics procedures.

The paper has two aims. The first is to argue the case for greater recognition of the role of the community sector and its research partners in policy development and implementation. The second aim is to highlight and discuss the internal institutional tensions and structural impediments facing researchers working closely with this sector. We document the roles the academic can play in such work, and argue that institutional change is required to support engaged researchers and increase the policy impact of community sector activities. The paper contributes to a gap in the literature by stimulating greater discussion within geography on how to approach and negotiate policy research with a broad spectrum of actors involved in policy-making (Pain, 2006).

We address our first aim by exploring the meaning of policy and how policy-making is represented in the higher education and research sector and by discussing the policy concerns and contributions of the movements with which we have worked. We then address our second aim by describing the various roles of the academic in engaged community-centred research, the institutional context for such work, and the tensions between competing priorities and performance measures. We give particular attention to 
Published in 2014 by Geographical Research 52(2):146-156.

the ethical issues we have faced and the challenges for research institutions in fostering critical research of community relevance. On that basis, the final section suggests ways forward.

\subsection{Policy-making and the community sector}

We have between us over twenty years' experience in natural resource management and housing research conducted across multiple Australian jurisdictions. In both arenas, communities and their representative organisations have been building institutional capacity by acquiring knowledge, undertaking research, advocating for reform to current practice and implementing diverse projects. Communities have also been directly involved in developing policy for adoption by their own organisations or by government agencies, and have challenged dominant policy imperatives and deficient policy instruments. Organisations we have worked with have played a role in preparing, instigating, and/or implementing policy change, a role that Huitema and Meijerink (2010) define as 'policy entrepreneuralism'. Policy entrepreneurs according to that definition are 'people willing to invest their resources in return for future policies they favour' (p. 27). These common efforts enable us to draw on insights and perspectives from across sectors and state jurisdictions, revealing core themes that cut across sector, location, community profile and policy context.

Sue Jackson's role in one of these research partnerships ${ }^{i}$ was advisor to an Indigenous organisation overseeing a project on national water reform. In many Australian water management contexts, Indigenous groups are seeking to renegotiate the terms of engagement with governments and to radically influence policy development and water 
Published in 2014 by Geographical Research 52(2):146-156.

allocation outcomes. A number is now closely involved in water policy development and have cogently argued that further policy action is required to realize economic benefits and sustainable environmental and social outcomes from water management. Research conducted by Jackson has been undertaken in partnership with Indigenous organisations that have established policy-making entities that operate 'across the boundaries of territorially defined jurisdictions' (Hajer, 2003, 190), a practice demonstrating 'a new spatiality of policy-making and politics' $(2003,179)$.

Louise Crabtree works with communities and organisations attempting to improve housing design and tenure options and on the policy implications of tenure models that articulate

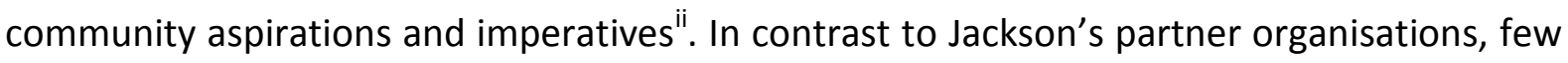
of these are directly involved in policy-making and some have fallen foul of extant policy. However, all are extensively involved in the development of internal policies and programs, which are occasionally adopted as best practice in public policy. As with the Indigenous organisations above, the housing organisations employ a strategy common to policy entrepreneurs which is to build coalitions, collaborate and promote ideas amongst networks (Huitema and Meijerink, 2010).

In light of our work, our concern lies in the common portrayal of the public sector as the sole locus of policy making, in contrast to more nuanced, processual understandings of policy-making as relational, dynamic and involving multiple stakeholders. The policy process assumed by Shergold (2011) and Australian research assessment frameworks resemble the traditional one described by Pain (2006) and Shore and Wright (2011) whereby academics 
Published in 2014 by Geographical Research 52(2):146-156.

provide advice on government policy in a linear transfer of knowledge (see Shergold, 2011; Norrie, 2012).

The spatial metaphors deployed reveal the construction of two separate worlds - one inhabited by the academic in the university or research institute, and the other by the public policy-maker in government. The academic is identified as 'knowledge broker' with calls commonly made for the broker, equipped with instrumental knowledge, to 'close the gap' or 'bridge the chasm' between the academy and the policy process (Thompson, 2011; Pannell and Roberts, 2009). In this 'elitist' conceptualisation of research utilization (Pain, 2006), the relevance of the research subject is not conceived as socially and politically constructed, the parameters and exclusions of the policy process appear relatively uncontested or stable (Peck, 1999) and the policy makers' 'unstable social products appear apolitical and self-evident' (Shore and Wright, 2011, 5). Idealised models of policy represent it as a reified object or field 'out there' to be managed clinically and instrumentally (Shore and White, 2011, 5).

Although many universities now have community engagement strategies, in the UK at least, some can be criticised for promoting university interests first, not those of the communities (mrs kinspaisby, 2008). Many of the definitions of community engagement upheld by the performance policies of Australian universities tend to be quite rarefied, stressing roles that include membership of government advisory bodies, expert panels, private sector consultant or witness. Such definitions reflect and reinforce traditional authoritarian assumptions regarding the location and deployment of rational knowledge and policymaking, often failing to recognise a wider array of actors with which one can engage to 
Published in 2014 by Geographical Research 52(2):146-156.

effect social change; although recently the definition has started to broaden within at least one university.

Moreover, the academic that is endorsed in this model is the distant 'expert' or 'knowledge broker' informing a spatially confined policy making arena, often at the national scale. For example, the ANU's Strategic Plan states that it will, inter alia, strive for excellence as a national and international policy resource:

Central to the outreach role of ANU is engagement with government, and building a critical mass of research and education excellence in public policy which will act as a resource for the nation and our region. Staff will be encouraged not only to achieve academic excellence in their discipline field, but also to contribute to the national and international debate and provide government and the community with the highest quality intellectual resource $(2011,5)$.

While community groups are recognized as stakeholders by the University of Western Sydney, for example, the assumption is still one of knowledge dissemination from the academic to the community. An alternative is presented by Pain's 'bottom-up' model that has researchers operating at the grassroots level which involves working with community and interest groups to effect change' $(2006,254)$. Pain urges geographers to 'rescale' common notions of policy research by working with local communities to define research problems and develop research skills. However, a more fulsome rescaling would also include recognising the policy-making capacity in the community or NGO sector and supporting its contributions to wider policy processes, similar to the examples referred to above. 
Published in 2014 by Geographical Research 52(2):146-156.

A focus on governance can help here by shifting scholars and practitioners from 'a preoccupation with the formal institutions of government' to an interest in diverse modes of governance, including collaborative partnerships and informal arrangements involving state agencies, non-government organisations, private sector agents (Lockwood et al., 2009, 170). Shore and Wright (2011) argue that policy needs to include 'not only those who govern but also conceive an active role for the governed, as well as the technologies that mediate between them' ( $p$ 12). Advancing an interpretative approach to policy, the field of research is defined as 'a social and political space articulated through relations of power and systems of governance', not a particular people, organisation, document or reified policy itself $(2013,11)$. Policy is conceptualised by Shore and Wright (2011) as a space that is formed, occupied and contested by a wide array of actors:

The importance of policy as a subject of anthropological research arises from the fact that policies are major instruments through which governments, companies, nongovernment organisations, public agencies and international bodies classify and regulate the spaces and subjects they seek to govern (p. 2.)

The initiatives we have been involved in are illustrative in this regard because they reflect the shifts in policy-making and politics identified by Hajer (2003) and Shore and Wright (2011); shifts that have been of interest to geographers for both their empirical effects (see Argent's 2011 introduction to a special edition of Australian Geographer, for example) and their influence on geographic knowledge production in the academy (see Castree, 2006). 
Published in 2014 by Geographical Research 52(2):146-156.

We provide an example from the first author's experience in the water management sector. In conjunction with the Executive Officer of the North Australian Indigenous Land \& Sea Management Alliance (NAILSMA), researchers initiated an innovation in stakeholder participation and learning: the Indigenous Water Policy Group (IWPG) (Jackson and Altman, 2009). Members of the IWPG are office bearers of north Australian Land Councils and senior executives of government water agencies (NT, QLD, WA). A specific aim of the IWPG project was to build the institutional capacity of Indigenous organisations to contribute to water policy making and implementation.

The aims and activities of this group represent a new practice of governance (Hajer, 2003) with the IWPG experimenting with alternative forms of problem solving by engaging in collaborative dialogue with government agency staff and researchers. Hajer (2003) observes that a recurring feature of such policy making models is the notion of mutual interdependence, and key to their success is that government agencies participate in, but do not dominate, discussions. Strong leadership by Indigenous organisers and opportunities for closed, Indigenous only, meetings ensured that this was the case. Mutual interest was evident from the start: water planners needed to develop ways of implementing the national water policy provisions relating to Indigenous access to water and participation in water planning while Indigenous leaders wanted to draw on knowledge of the very complex water sector to position themselves and design their own corporate policies and strategies. Research on institutional barriers provided a foundation for policy development within the Group and the approach has been recommended to Land Councils, Indigenous NGOs, and 
Published in 2014 by Geographical Research 52(2):146-156.

water advisory committees. The group developed policies that were presented to the World Water Forum in Turkey in 2010. Its efforts resulted in a change to NT government policy by providing for 'Strategic Indigenous Reserves' of water to be included in some new water plans (Jackson and Barber, 2013; O’Donnell, 2013). The IWPG is now a recognised model of collaboration and consensus building.

The policy making practices and networks of the community sector are clearly critical to political transformation and therefore a legitimate focus for research inquiry and yet we find insufficient recognition of this capacity within current debates about and measures of research impact and influence. In the following section, we examine the academic's role in such collaborations, the kind of research practice such an orientation entails, and whether it is sufficiently supported by higher education and research organisations and institutions.

\subsection{Institutional tensions and ethical issues}

The claim that the impact of Australian research is under-realised has most recently been articulated by Peter Shergold, Chancellor of the University of Western Sydney and former senior public servant (2011). According to Shergold, incentive structures, university culture and measures of impact are barriers that prevent academics from taking their research into the realm of public policy and collaborating more effectively with the public service:

...if you look at how universities are funded, if you look at how the value of research is measured, and therefore if you look at how academics respond, it is still largely in terms of the influence they have within academia through citations, through peerreviewed journals... (cited in Thompson, 2011). 
Published in 2014 by Geographical Research 52(2):146-156.

The measures of research excellence currently include journal publications, peer esteem and application (referring to commercial income from research) (Commonwealth of Australia, 2011). Measures intended to capture research application include patents, registered designs and other commercial outputs, while measures intended to capture esteem extend into policy to the extent of membership of statutory committees (Commonwealth of Australia, 2011). Employment performance criteria similarly focus on securing competitive grant or consultancy income as a key measure of success.

In addition to reforms to incentive structures, Shergold calls for a better negotiated understanding of the expectations of the respective parties-researchers and public servants-and agreement on the contractual relationship, publication rights, timeframes, etc. Whether or not one agrees that incentives are the only barrier to policy uptake (for a personal account of one academic's negative experience in communicating policy advice, see Altman, 2013), it is not difficult to see merit in Shergold's call for clarity and equality in research collaborations, or for a better balance in measuring impact to account for policy influence. Others have made similar observations noting, for example, that research assessment exercises 'define academic 'value' in rather narrow ways' (Castree, 2006) and send out 'negative messages to those interested in policy-relevant research' (Pollard et al., 2000: 245; Altman, 2013).

As research institutions struggle to appropriately recognise and reward relevance and engagement, community-based researchers must answer to institutional metrics and norms alongside the demands of the research and the expectations and agendas of nongovernment groups that are often under-resourced across multiple dimensions. Generating 
Published in 2014 by Geographical Research 52(2):146-156.

impact is a complicated process (Conlon et al., 2014) and contributing to both scholarly understanding and addressing real world problems is an 'extraordinarily difficult' task (Hollander, 2011, 265) that requires time and effort in collaboratively conceptualising and framing the problem(s), agreeing to objectives, outcomes, methods and accountability measures of relevance to all parties, under conditions that are often financially and temporally constrained (see Casteldon et al., 2012). These demands and the tensions they raise for the academic are well described in the extensive literature on participatory action research (see for example Clark, 1972; Greenwood and Levin, 1998) and by those geographers who seek to bring their 'spatial sensitivity' to participatory practices (mrs kinpaisby, 2008, p. 292; Pain, 2004; Cahill, 2007; Cahill et al., 2007).

Research institutions currently provide their staff with little, if any, support to navigate the complexities, better resolve the tensions, or develop the skills to overcome barriers to simultaneously making solid contributions to both the academy and community partners. We are aware of little research in Australia that has sought to define or explore community sector perspectives on research relevance - insights which would seem to be crucial to improving research impact and affecting change in wider society. In light of our collective experience, we offer the following observations on the academic's role in collaborative community-based research. Each of these highlights a number of issues that generated tensions in our collaborations and are reflective of this work's demands: balancing independence and control; taking time to negotiate access to the research setting and build relationships; navigating ethics; and, demonstrating scholarly significant results. 
Published in 2014 by Geographical Research 52(2):146-156.

Firstly, there is a role of building capacity by analysing the existing situation to provide information, critique and possible alternatives, in useful and relevant formats. Relevant and useful research has to accord closely with community group experiences, meaning that researchers have to spend time in organisations 'observing what they do, how they think, and what problems and constraints they face' (Beyer, 1997, 19). Researchers need to understand group norms regarding information collection and distribution and how the research will be used (Beyer, 1997). Thus the quality of research relationships with a community may depend on demonstrating willingness on the part of the academic and her/his institution to devote a significant amount of time to these activities and, in doing so, develop and sustain a deep accountability. Roa et al. (2009) concluded that NZ's performance-based research funding model generated significant barriers to increasing the volume, scope and quality of environmental research for Māori. Their assessment acknowledged that 'ethical, accurate, authentic, trusted and used research' took longer to complete than did 'normal' research and that 'Performance Based Research Funding discourages researchers from engaging in such cross-cultural processes' because international journals demand priority (Roa et al., 2009: 234).

Under existing institutional funding mechanisms, the peer-reviewed journal article or scholarly book are privileged outputs, but community groups place far less value on publishing results in academic outlets or formats. Conflicting priorities between academia and the community sector for very different products can place considerable pressure on a researcher. The work involved in translating complex theoretical principles and arguments 
Published in 2014 by Geographical Research 52(2):146-156.

into practically workable models and policy through methodologies that are themselves also informed by theory is substantial, time-consuming and conceptually challenging. One can thrive in such a space, finding the challenge exciting and the work's successful accomplishment satisfying, but we have found that the demands are often underacknowledged and the policy or other outputs are more difficult to have recognised by research institutions as scholarly products, regardless of their theoretical basis.

Further, although one's institution may place little value on plain language documents, such as those that explain research aims and results, there are countervailing pressures to create such materials. Researchers must comply with human ethics frameworks, for example, and these regard production of such documents as a standard means of satisfying community expectations, demonstrating relevance and obtaining consent. Researchers have obligations to their research partners, necessitating that we adopt the principle of 'giving back' by publishing in outlets relevant to practitioners, no matter their weighting under research performance frameworks. In a similar vein to Beyer's (1997) interrogation of the reward systems for management research in the US, we find it instructive to imagine how differently motivated researchers might be if promotions and grants were dependent on successfully publishing some of their work in outlets targeting the non-government sector, or on policy or community sector esteem.

Nonetheless, academic publication is an essential practice; it is an important way of obtaining peer review of one's work, as well as engaging with the literature and contributing to theoretical perspectives. There is also a strategic benefit to publishing, inasmuch as published results will be seen by most decision-makers as more authoritative. However, 
Published in 2014 by Geographical Research 52(2):146-156.

non-researchers, particularly those who may have had negative experiences with the research sector, such as some Indigenous peoples and community groups, tend to see writing journal papers as a self-interested pursuit intended to further an academic's career; one that has little impact on practice or policy. That publication performance is now so central to academic career advancement may contribute further to this caricature of researcher motivations. In our experience, the narrow focus on academic production is a source of considerable tension and it has affected relationships between researchers and community group members in the water policy work cited above.

A second proposed role is to bring financial, institutional and/or human resources to the community sector, which is renowned for being unable to offer these to its academic partners. This imbalance creates several issues. Most competitive academic funding programs require some form of monetary or in-kind contribution from research partners - a factor that can immediately exclude many potential partners, especially newly forming or marginalised groups. In addition, the often low resource base of community organisations can place additional pressures on researchers' time and roles, if partners seek to utilise the researcher to perform tasks otherwise performed in-house. Although this activity might provide data for research, the boundaries between participatory action research, misuse and co-option can become blurred. The issue of independence is taken up further below.

Thirdly, there is a role of persuading policy-makers to see the need for and means to reform or implement policy through reports, media statements and personal representations. Some policy analysts recognize the importance of language, rhetoric and persuasion to policy processes (Shore and Wright, 2011) but, as discussed above, tracking or measuring this 
Published in 2014 by Geographical Research 52(2):146-156.

'promotional' work can be difficult. Academics working at the coalface of controversial policy or practical innovation with groups on the margins of political influence can find the political climate hostile to the inclusion of critical or innovative voices in formal advisory bodies, for example (see Altman, 2013).

Fourthly, there is a role to play in maintaining sufficient independence and providing expertise that in some large part comes from contributing to scholarly debates and theorybuilding and from the principles of appropriate research methodologies. However, this is a re-imagined expertise to that of the knowledge broker who plays a 'straddling' or 'bridging' role between the two worlds of the research sector and those of policy-makers. The assertion of a 'bridging' function reifies the perception of a distinction between research and policy that sits ill with interpretations of policy-making as a complex, dynamic and relational process. According to Pain,

power has been undertheorised in these debates, and should be seen as reflexive and shifting. Experience of policy research is less 'us and them' and more a relational process which is always becoming, as geographers work between worlds (Routledge, 1996; 2004) in an 'endless moving between' ideas and policy (Massey, 2002: 645) (Pain, 2006: 255).

The academic needs to therefore negotiate how to gain a sympathetic understanding of the actors' policy worlds, their organisation and its situation, while avoiding cooption or partisanship. Such self-reflexivity requires that one sustain the tension between 'insider' and 'outsider' perspectives (Shore and Wright, 2011), so as retain some degree of control of the 
Published in 2014 by Geographical Research 52(2):146-156.

research process (Hollander, 2011). Meeting the different interests and expectations of one's research organisation, disciplinary colleagues, and community partners is no easy task in politically contested policy matters. Given the institutional issues discussed above, engaged researchers may find themselves struggling to assert a degree of independence from the imperatives of their own institution, which are also operating in an increasingly privatised world, and public suspicions of academic advocacy.

Consideration of this last role brings us to the challenging issue of navigating research ethics, as illustrated by a vignette from the housing work. Few projects involved formal agreements and in most instances Louise Crabtree was keen to validate interview transcripts and/or research outputs with participant organisations prior to publication. In one case, some community members objected to publication on the grounds that findings were too negative. The paper could not be published without inclusion of the substantive material deemed unacceptable by the partner organisation. Despite being formally entitled under university ethics protocols to publish irrespective of such objections, the researcher elected not to. Formal ethics protocols in this instance did not provided guidance on how to negotiate this sensitive terrain, leaving the researcher with no clear path to publication without transgressing personal ethics standards.

\subsection{Conclusion}

Today a broad range of hybrid governance strategies are practiced in response to complex societal problems and they depend for their efficacy on support from diverse domains of research and social action (Lemos and Agrawal, 2006). Policy will therefore benefit from 
Published in 2014 by Geographical Research 52(2):146-156.

diverse expertise and effective participation from all sectors of the public. Australia's research evaluation framework does not recognise the value of this plurality or ensure it is reflected in its measures of research quality and impact, and in the systems of support for researchers to capably engage with the community sector, address its research needs, assist in building its institutions and enhance its influence over public policy development and implementation. Research managers who apply outdated models of classical/modernist institutions and policy-making will inevitably truncate opportunities for research to be useful and relevant. Moreover, adherence to the state-centred, elitist model of policymaking may well result in a bias towards forms of scholarship that meet the wishes of privileged stakeholders over those that respond to the needs of groups with limited capacity or resources to influence policy (Sheppard in Castree, 2006: 764).

The logical extension of the expectation for more engaged, policy relevant research is a more politically engaged academic and this requries that we find ways of addressing power and politics not only in the developing notion of impact but in our own practices (Pain, 2014; 2006). Yet we find many impediments to political engagement with progressive movements, both internal and external to the research institutions in which we are and have most recently been employed ${ }^{i i i}$. We argue that the role expected of a researcher under a more nuanced model of engaged or participatory policy development demands different ways of working than does the conventional linear and competitive model of research impact and that this is not well understood. Engaged research is not easy and does not always accord well with workplace performance metrics and protocols, or present as advantageous in the academic job market. Efforts to incorporate and measure impact remain elusive (Norrie, 
Published in 2014 by Geographical Research 52(2):146-156.

2012; Johnston, 2006) and so demonstrating quality is usually more time-consuming than where it involves the provision of a list of peer-reviewed publications. Left unattended, these obstacles are likely to militate against involvement in policy research with the community sector.

Not surprisingly incentive structures have attracted the attention of some policy-oriented researchers, including geographers, and critics of the higher education sector in their attempts to make research more relevant, more capable of affecting change in society and to increase research budgets. There can be little doubt that they will play some part in influencing researchers' choices and behaviours, and they may well deter researchers from engaging with the community sector, particularly if they encourage risk aversion; an outcome of neoliberal trends in research assessment that Sheppard (Castree 2006) sees as likely. Participatory research with small organisations, grassroots movements and activists is especially endangered by the impact agenda (Pain, 2014).

Castree reminds us that 'research assessment systems are thus themselves political technologies because they aim to shape what counts as 'valid' and 'valuable' knowledge' (2006, 749). At a time when policy-relevant work is called for, institutional and sector pressures may be creating structural incentives that undermine academics' capacity or inclination to do such work. Academic training is accordingly influenced by this climate, with very little training provided in conducting engaged research appropriately and effectively, interpreting, engaging with and influencing policy (or policy-makers), or demonstrating the relevance or impact of engaged research (Pain, 2006). 
Published in 2014 by Geographical Research 52(2):146-156.

There is therefore further work to be done to overcome the barriers to engaging with the community sector - in negotiating access to the research settings in which the community sector operates and the terms of consequent partnerships. To start, we table three main issues. Firstly, more effort is needed to equip researchers in negotiating the terms of research collaborations up-front, providing time and resources to develop sustainable relationships and agree on research questions and methods. Researchers should seek to understand the research setting, political imperatives and agendas of their partners and in return seek from their partners understanding of the research cultures affecting their practices. It is imperative that institutional impediments to reciprocity are acknowledged and addressed as far as possible (Jacobs, 2002).

Secondly, there could be a greater role for seed-funding and open-ended, funding options to support the kind of action research that emphasises cooperative or collaborative problem-framing and interactive scoping of projects, without the requirement for community organisations to contribute funds. A number of studies nominate the joint design of projects as a critical determinant of success in participatory projects involving indigenous people at least (Cullen-Unsworth et al., 2012, see also Casteldon et al., 2012). Moreover, by valuing 'slow research', institutions will be better equipped to support the generation of long term commitments to participatory practices (mrs kinpaisby, 2008; Conlon et al. 2014).

Lastly, there is a need for further training in and dialogue about 'ethics in practice', as distinct from compliance with formal protocols or 'procedural ethics' (Guillemin and Gillam, 2004). Within our discipline we have a valuable source of ideas in the methodological 
Published in 2014 by Geographical Research 52(2):146-156.

discussions amongst 'participatory geographers' (mrs kinpaisby, 2008; Cahill et al. 2007; Kindon et al. 2007; Manzo and Brightbill, 2007) and these need to be taken up in dialogue with institutional ethics processes (see Martin, 2007). We concur with the argument of Chenhall et al. (2011) that 'the reductionist nature of the (Australian) application process means that there is currently no arena for discussing the complex ethical issues that arise from qualitative research' (p. 13). While there is no tool box of ready-made methods to apply (Shore and Wright, 2011), exchanges between experienced and less-experienced researchers about research ethics and real-life contextualisations of ethical standards will undoubtedly contribute to building the awareness, self-reflexivity and confidence so essential in addressing the emotional engagements and responsibilities that arise in tackling sensitive and complex research topics with communities (Cahill, 2007; Martin, 2007). Critical reflexivity requires an 'ethnographic sensitivity' made possible by 'continual oscillation between insider and outside perspectives' (Shore and Wright 2011, 12). If such a disposition is the hallmark of social anthropology, as Shore and Wright (2011) believe, then geography could also benefit from more frequent and extensive dialogue with its cognate discipline of anthropology.

Were the Australian research framework underpinned by a more expansive and democratic governance paradigm, it might serve to encourage greater and deeper cooperation between researchers and social actors who engage in policy research and development from a position currently not recognised by institutional conceptions of the policy and knowledge production process. To achieve such a change will require activism from within higher 
Published in 2014 by Geographical Research 52(2):146-156.

education and research institutions. If such activism can be supported by the many publics that have a stake in policy-making, not only public servants, it may be realised more quickly and effectively and in turn will likely result in closer, more trusting research partnerships in which due attention is given to social impact and relevance.

\section{Acknowledgments}

The authors wish to acknowledge their respective partner community organisations and to thank the journal's reviewers as well as a number of colleagues who provided helpful comments on an early draft of the paper: Jon Altman, Nicole Cook and Simon Batterbury.

\section{References}

Altman, J.C., 2013: Arguing the Intervention. The Journal of Indigenous Policy 14, 1-156.

Amara, N., Ouimet, N. and Landry, R., 2004: New Evidence on Instrumental, Conceptual and Symbolic Utilization of University Research in Government Agencies. Science Communication 26(1), 75-106.

Argent, N., 2011: What's New about Rural Governance? Australian perspectives and introduction to the special issue. Australian Geographer 42(2), 95-103. 
Published in 2014 by Geographical Research 52(2):146-156.

Australian National University 2011: ANU by 2020, Office of Vice Chancellor, ANU, Canberra, http://about.anu.edu.au/ documents/strategic-plans/anu-2020-strategy.pdf, accessed 15 March 2013.

Batterbury, S., 2013: Who are the radical academics today? March 1, 2013, http://simonbatterbury.wordpress.com/2013/03/01/where-have-the-radicalscholarsgone/, accessed June 142013.

Beyer, J.M., 1997: Research utilization: Bridging a Cultural Gap Between Communities, Journal of Management Inquiry 6, 17-22.

Blomley, N. K., 1994: Editorial: Activism and the Academy, Environment and Planning D: Society and Space 12, 383-385

Blomley, N.K., 1995: Editorial: Reply to Tickell, Environment and Planning I): Society and Space $13,239-240$.

Bridge, G. and Perreault, T., 2009: Environmental Governance in N. Castree, D. Demeritt, D. Liverman and Rhoads, B. (eds) A Companion to Environmental Geography. Blackwell Publishing, Oxford, 475-497.

Briggs, S.V., 2006: Integrating policy and science in natural resources: Why so difficult? Ecological Management and Restoration 7 (1), 37-39. 
Published in 2014 by Geographical Research 52(2):146-156.

Cahill, C., 2007: Repositioning ethical commitments: Participatory Action Research as a relational praxis of social change, ACME: An International E-Journal for Critical Geographies, 6 (3), 360-373.

Caitlin, C., F. Sultana and Pain, R., 2007: Participatory Ethics: Politics, Practices, Institutions, ACME: An International E-Journal for Critical Geographies, 6 (3), 304-318

Casteldon, H., V. Sloan Morgan, and Lamb, C., 2012: "I spent the first year drinking tea": Exploring Canadian university researchers' perspectives on community-based participatory research involving Indigenous peoples, Canadian Geographer 56(2), 160-179.

Castree, N., 1999: "Out there? In here", Domesticating critical geography, Area 31(1), 81-86.

Castree, N., 2010: Contract research, universities and the 'knowledge society': back to the future' in, C. Allen and Imrie R. (eds), The Knowledge Business: the Commodification of Housing and Urban Research, Ashgate, Farnham UK, 221-240.

Castree, N., 2006: Research assessment and the production of geographical knowledge, Progress in Human Geography 30, 747-782.

Chenhall, R., Senior, K. and Belton, S., 2011: Negotiating human research ethics, Anthropology Today 29 (5): 13-17. 
Published in 2014 by Geographical Research 52(2):146-156.

Clark, P.A., 1972. Action Research and Organisational Change. Harper and Row, London;

Commonwealth of Australia 2011: ERA 2012 Submission Guidelines. Commonwealth of Australia, Canberra.

Conlon, D., Gill, N., Tyler, I., Oeppen, C., 2014: Impact as Odyssey, ACME: An International EJournal for Critical Geographies, 13(1), 33-38.

Cullen-Unsworth, L., R. Hill, J.R. Butler, and Wallace, M., 2012: A research process for integrating Indigenous and scientific knowledge in cultural landscapes: principles and determinants of success in the Wet Tropics World Heritage Area, Australia, The Geographical Journal, 178, 351-365.

Gill, N., 2006: What is the problem? Usefulness, the cultural turn, and social research for natural resource management, Australian Geographer 37 (1), 5-17.

Greenwood, D.J., Levin, M., 1998: Introduction to Action Research: Social Research for Social Change. Sage, London.

Guillemin, M., Gillam, L., 2004: Ethics, reflexivity, and 'ethically important moments' in research, Qualitative Inquiry 10(2), 261-280. 
Published in 2014 by Geographical Research 52(2):146-156.

Hajer, M., 2003: Policy without Polity? Policy Analysis and the Institutional Void, Policy Sciences 36(2), 172-195.

Hollander, J.B., 2011: Keeping control: the paradox of scholarly community-based research in community development, Community Development Journal 46, 265-272.Huitema, D. and Meijerink, S., 2010: Realizing water transitions: the role of policy entrepreneurs in water policy change, Ecology and Society 15(2), 26.

Jackson, S. and Altman, J.C., 2009: Indigenous rights and water policy: perspectives from tropical northern Australia, Australian Indigenous Law Review 13(1): 27-48.

Jackson, S. and Barber, M., 2013: Indigenous water values and resource governance in Australia's Northern Territory: current progress and ongoing challenges for social justice in water planning, Planning Theory and Practice DOI: $10.1080 / 14649357.2013 .845684$

Jacobs, K., 2002: Connecting Science, Policy and Decision- Making: A Handbook for Researchers and Science Agencies. NOAA Office of Global Programs, Boulder, Colorado.

Johnston, R., 2006: Research Quality Assessment and Geography in Australia: Can Anything be Learned from the UK Experience?, Geographical Research 41(1), 1-11. 
Published in 2014 by Geographical Research 52(2):146-156.

Jones, A. and Seelig, T., 2004: Understanding and enhancing research-policy linkages in Australian housing: a discussion paper, AHURI Positioning Paper No. 75 Australian Housing and Urban Research Institute, Melbourne.

Kindon, S., Pain, R. and Kesby, M. (eds) 2007: Connecting People, Participation and Place: Participatory Action Research Approaches and Methods. London: Routledge.

Lemos, M.C. and Agrawal, A., 2006: Environmental Governance, Annu. Rev. Environ. Resour., 31, 297-325.

Lockwood, M., Davidson, J., Curtis, A., Stratford, E. and Griffith, R., 2009: Multilevel Environmental Governance: lessons from Australian natural resource management, Australian Geographer 40 (2), 169 - 186.

Manzo, L. and Brightbill, N., 2007: Towards a participatory ethics. In, Kindon, S., Pain, R. and Kesby, M.,. (eds) Connecting People, Participation and Place: Participatory Action Research Approaches and Methods. London: Routledge, pp. 33-40.

Martin, D.G., 2007: Bureacratizing Ethics: Institutional Review Boards and Participatory Research, ACME: An International E-Journal for Critical Geographies 6 (3), 319-328

Mitchell, D., 2008: Confessions of a desk-bound radical, Antipode 40(3), 448-454. 
Published in 2014 by Geographical Research 52(2):146-156.

mrs kinpaisby, 2008: Taking stock of participatory geographies: envisioning the communiversity, Transactions of the Institute of British Geographers, 33, 292-299.

Norrie, J., 2012: Universities to explain benefits of research to 'end-users', The Conversation, 5 June 2012.

O'Donnell, M. 2013: The National Water Initiative, native title rights to water and the emergent recognition of indigenous specific commercial rights to water in Northern Australia, The Australasian Journal of Natural Resources Law and Policy, 16, 83-100.

Pain, R., 2004; Social geography: participatory research, Prog Hum Geogr 28, 652-63.

Pain, R., 2006: Social geography: Seven deadly myths in policy research, Prog Hum Geogr $30(2), 250-59$.

Pain, R., 2014: Impact: Striking a blow or walking together? ACME: An International EJournal for Critical Geographies 13(10), 19-23.

Pannell, D. and Roberts, A., 2009: Conducting and delivering integrated research to influence land-use policy: salinity policy in Australia, Environmental Science and Policy 12, 1088-98.

Peck, J., 1999: Grey geography? Transactions of the Institute of British Geographers 24, 1315 
Published in 2014 by Geographical Research 52(2):146-156.

Pollard, J., Henry, N., Bryson, J. and Daniels, P., 2000: Shades of grey? Geographers and policy, Transactions of the Institute of British Geographers 25, 243-248.

Radice, H., 2013: How We Got Here: UK Higher Education under Neoliberalism, ACME: An International E-Journal for Critical Geographies 12 (3), 407-418.

Roa, T., Beggs, J.R., Williams, J. and Moller, H., 2009: New Zealand's Performance Based Research Funding (PBRF) model undermines Maori research, Journal of the Royal Society of New Zealand 39(4), 233-238.

Roux, D.J., Stirzaker R.J., Breen C.M., Lefroy E.C., and Cresswell, H.P., 2010: Framework for participative reflection on the accomplishment of transdisciplinary research programs, Environmental Science and Policy 13, 733-741.

Shergold, P. 2011: Seen but not heard, The Australian, May 42011.

Shore, C. and Wright, S., 2011: Conceptualising Policy: Technologies of Governance and the Politics of Visibility in C. Shore, S. Wright, and Pero, D. (eds) Policy Worlds: Anthropology and the Analysis of Contemporary Power, EASA Series, Berghahn, Oxford, 1-26.

Tickell, A., 1995: Reflections on 'Activism and the Academy', Environment and Planning D: Society and Space 13, 235-237. 
Published in 2014 by Geographical Research 52(2):146-156.

Thompson, M., 2011: Let's Close the Gap Between Academics and Policy-Makers: Peter Shergold on Changing the System, The Conversation, 8 November 2011, http://theconversation.com/lets-close-the-gap-between-academics-and-policy-makerspeter-shergold-on-changing-the-system-4191.

van Vliet, W., 2003: So what if housing research is thriving? Researchers' perceptions of the use of housing studies, Journal of Housing and the Built Environment 18, 183-199.

Ward, K., 2006: Geography and Public Policy: Towards Public Geographies, Progress in Human Geography 30, 495-503. 
Published in 2014 by Geographical Research 52(2):146-156.

\section{Endnotes}

i The projects' collective aims have included building the capacity of Indigenous organisations to more effectively influence the National Water Initiative (Jackson and Langton, 2012; Jackson et al. 2011), improving the equity of water allocation outcomes and the degree to which Indigenous people are able to represent their interests in water management activities.

ii In deference to community concerns described later, this discussion does not refer to any singular project, location or organisation.

iii When the paper was conceived in 2012 Sue Jackson was working for the CSIRO. 